\title{
Влияние топографических дефектов на супергидрофобные свойства покрытий на основе ZnO
}

\author{
() А.Э. Муслимов ${ }^{1}$, А.Ш. Асваров ${ }^{1,2}$, Н.С. Шабанов ${ }^{3}$, В.М. Каневский ${ }^{1}$ \\ ${ }_{1}^{1}$ Федеральный научно-исследовательский центр „Кристаллографиия и фотоника“ РАН, Москва, Россия \\ ${ }^{2}$ Институт фризики Дагестанского федерального исследовательского центра РАН, Махачкала, Россия \\ ${ }^{3}$ Дагестанский фредеральный исследовательский центр РАН, Аналитический центр коллективного пользования, \\ Махачкала, Россия \\ E-mail: amuslimov@mail.ru
}

Поступило в Редакцию 8 мая 2020г.

В окончательной редакции 18 мая 2020г.

Принято к публикации 27 июня 2020 г.

\begin{abstract}
Приведены результаты исследования гидрофобных свойств покрытия $\mathrm{ZnO}$ с различной морфологией поверхности. Показано, что для случая образцов $\mathrm{ZnO}$ с нанометровой шероховатостью поверхности реализуется состояние Венцеля, а для микроструктурированных образцов - состояние Касси. Для образца с многомодальной шероховатостью поверхности достигнуто супергидрофобное состояние с краевым углом, равным $151^{\circ}$, и работой адгезии $8.82 \mathrm{~mJ} / \mathrm{m}^{2}$. Продемонстрировано, что наличие микрометровых дефектов на поверхности супергидрофобных образцов приводит к нестабильности состояния Касси, а при увеличении радиуса капель воды реализуется переход Касси-Венцеля.
\end{abstract}

Ключевые слова: $\mathrm{ZnO}$, супергидрофобное состояние, переход Касси-Венцеля.

DOI: 10.21883/PJTF.2020.19.50037.18371

Уникальное сочетание свойств и морфологическое многообразие форм оксида цинка обусловливают неугасающий интерес к нему и непрерывное расширение областей его применения. Являясь радиационно стойким полупроводниковым материалом с шириной запрещенной зоны $3.37 \mathrm{eV}$ и обладая превосходными электрофизическими, оптическими, пьезоэлектрическими, газои фоточувствительными свойствами, оксид цинка уже занял достойное место в различных приборах микро-, оптоэлектроники и сенсорики. С развитием биомедицинских технологий оказались востребованными такие свойства оксида цинка, как экологическая безопасность и биосовместимость [1,2]. Для непосредственного применения оксида цинка в биотехнологиях зачастую необходимо достижение супергидрофобного состояния в покрытиях на его основе, обеспечивающего устойчивость к биообрастанию и загрязнениям неорганической и органической природы. Исследованию гидрофильных и гидрофобных свойств оксида цинка посвящено много работ $[3,4]$. Традиционно гидрофобными считаются покрытия, контактный угол смачивания водой $\theta$ которых превышает 90 . Среди высокогидрофобных поверхностей $\left(\theta>120^{\circ}\right)$ особый практический интерес представляют так называемые супергидрофобные поверхности, характеризующиеся углом смачивания $\theta>150^{\circ}$. Полное несмачивание $\left(\theta=180^{\circ}\right)$ в природе не реализуется, поскольку всегда существует взаимодействие между фазами.

Сверхгладкая поверхность оксида цинка является гидрофильной, однако при модифицировании поверхности $\mathrm{ZnO}$ путем формирования на ней упорядоченных и разупорядоченных микро- и наноструктур возможно дости- жение контактных углов смачивания водой $\theta>90^{\circ}[5,6]$. Очевидно, что реальные поверхности не являются идеально плоскими и всегда имеют некоторую минимальную шероховатость [7]. В то же время контактный угол для шероховатых поверхностей сильно отличается от контактного угла для плоских поверхностей того же химического состава и зависит от микроморфологии поверхности и величины шероховатости. В зависимости от шероховатости твердой поверхности традиционно рассматриваются две модели: состояние Венцеля и состояние Касси, теоретически описывающие область контакта капли жидкости с поверхностью. Если шероховатая поверхность смачивается пленкой жидкости, то реальная площадь контакта будет больше видимой в $r$ раз, где $r$ - коэффициент шероховатости, который определяется как отношение реальной площади поверхности контакта к ее проекции на геометрическую плоскость. Это равновесное состояние описывается моделью Венцеля. Могут возникать ситуации, когда при смачивании шероховатых поверхностей внутри полостей сохраняются пузырьки воздуха типа воздушной подушки. Краевой угол при смачивании таких поверхностей будет зависеть от соотношения площадей контактов жидкость-газ и жидкость-твердое тело в видимом контакте жидкости с поверхностью. В этом случае поверхность будет обладать гидрофобными свойствами и описываться моделью Касси. Для повышения гидрофобных свойств используется процедура формирования на поверхности исследуемых материалов периодической микротекстуры $[8,9]$. В то же время представляются интересными исследования твердых тел с многомодальной шероховатостью поверхности, которая открывает широкие возможности 
управления гидрофобными свойствами. Следует отметить, что состояние Касси является метастабильным и возможен необратимый переход в термодинамически устойчивое состояние Венцеля. Среди основных факторов, определяющих переход Касси-Венцеля, рассматриваются давление, нагрев, вибрации и испарение капли [10], тогда как влияние топографических микродефектов, которые могут присутствовать на реальной поверхности, на стабильность состояния Касси практически не изучено. В первую очередь присутствие микродефектов скажется на стабильности состояния Касси и вероятности необратимого перехода Касси-Венцеля при увеличении размеров осаждаемых капель воды.

Рассмотрим модель сферической капли воды, осажденной на шероховатую поверхность с псевдосферическими ямками-дефектами. Оказываемое каплей воды давление $p$ на поверхность будет расти с увеличением радиуса капли $R$. Вследствие этого гидродинамические процессы на границе капля воды-дефект будут протекать иначе, чем на остальной границе раздела. В настоящей работе впервые исследуется устойчивость супергидрофобного состояния поверхности слоя $\mathrm{ZnO}$ в зависимости от ее топографической однородности и размеров осаждаемых капель воды. Рассматриваются слои $\mathrm{ZnO}$ с различной морфологией поверхности: зернистая, с пластинчатой микроструктурой, с комбинированной шероховатостью микромасштаб-наномасштаб.

Три типа образцов $\mathrm{ZnO}$ с различной морфологией поверхности были получены на подложках сапфира и кремния методом химического осаждения из газовой фазы из паров цинка и кислорода. Тип 1 (рис. 1,a) зернистая пленка $\mathrm{ZnO}$, осажденная на подложку $C$-сапфира (базисная плоскость). Тип 2 (рис. 1,b) - микроструктура $\mathrm{ZnO}$, сформированная с использованием катализатора $\mathrm{Au}$ на подложке $R$-сапфира (ромбоэдрическая плоскость). Тип 3 (рис. 1,c) - упорядоченная структура $\mathrm{ZnO}$, полученная на кремниевой подложке-шаблоне с предварительно сформированным микрорельефом в виде квадратных ячеек с периодом $8 \mu \mathrm{m}$.

Микроскопические исследования проводились на растровом электронном микроскопе Jeol Neoscope 2 (JCM-6000). Для анализа гидрофобности/гидрофильности микроструктурированной поверхности оксида цинка применялась методика сидячей капли. Капли дистиллированной воды радиусом $0.5-0.7$ и $2 \mathrm{~mm}$ с помощью шприца помещались на горизонтальную поверхность образцов. Оптическая визуализация капли на поверхности осуществлялась с помощью цифровой фотокамеры. Ось объектива камеры размещалась на уровне границы раздела капля воды-поверхность образца. Контактный угол определялся по методике, описанной в [11]. Оптические исследования проводились с использованием оптического микроскопа Levenhuk.

Поверхность образца типа 1 характеризуется зернистой структурой с размерами зерен порядка 50-100 nm и высокой плотностью межзеренных границ (рис. 1, $a$ ). Форма капли воды радиусом $\sim 0.5 \mathrm{~mm}$, нанесенной на поверхность образца типа 1, представлена на вставке к рис. 1,a. Контактный угол $\theta=73^{\circ}$, что свидетельствует о смачиваемости такой поверхности $\mathrm{ZnO}$ водой (состояние Венцеля). Поверхность образца типа 2 (рис. $1, b)$ отличалась пластинчатой микроструктурой с редкими включениями структур $\mathrm{ZnO}$ игольчатой формы. Следует отметить, что в данном случае не реализовался рост массива вискеров $\mathrm{ZnO}$ по механизму пар-жидкость-кристалл, характерному для каталитического синтеза с использованием $\mathrm{Au}$ [12]. По всей видимости, играет важную роль $R$-ориентация сапфировой подложки. $R$-плоскость сапфира обладает псевдосимметрией четвертого порядка, и пленки $\mathrm{ZnO}$ на такой подложке растут традиционно вдоль оси $[11 \overline{2} 0][13,14]$. Возможно, также оказывает влияние вероятное присутствие на границе раздела соединений типа $\mathrm{Au}_{1.2} \mathrm{Zn}_{8.8}, \mathrm{AuZn}_{3}$, $\mathrm{AuZn}$ [10]. Согласно результатам исследований формы капли радиусом порядка $0.7 \mathrm{~mm}$ (рис. $1, b$, вставка) и оценке контактного угла $\theta=120^{\circ}$, на поверхности образца типа 2 реализуется состояние Касси. Электронномикроскопическое исследование поверхности образца типа 3 (рис. 1,c) продемонстрировало присутствие на поверхности периодических микроструктур $\mathrm{ZnO}$ типа „кактусов“ с множеством наноигл. Период микрорельефа соответствует периоду кремниевой подложкишаблона. Форма капли воды радиусом $0.7 \mathrm{~mm}$ и контактный угол $\theta=151^{\circ}$ (рис. $1, c$, вставка) свидетельствуют о том, что на поверхности данного образца реализуется состояние Касси.

Причиной кардинальных различий в смачиваемости поверхности образцов трех типов являются особенности морфологии поверхности $\mathrm{ZnO}$ и ее шероховатость. Величина шероховатости поверхности образца типа 1 достигает нескольких нанометров, отсутствуют крупные выступы, а дисперсность зерен незначительна, что обусловливает наблюдаемые гидрофильные свойства. Образец типа 2 обладает развитой поверхностью, и его шероховатость многократно превышает аналогичный параметр для образца типа 1. Помимо этого разупорядоченное расположение пластинчатых микроструктур $\mathrm{ZnO}$ предполагает наличие глубоких пустот между ними, некоторые из таких пустот могут быть заполнены смачивающей водой, а в остальных может сохраняться воздушная подушка. Поэтому поверхность образца типа 2, скорее, характеризуется как гидрофобная, нежели как высокогидрофобная. Для образца типа 3 благодаря совмещению микромасштабной и наномасштабной шероховатости реализуется „эффект лотоса“ $[15]$, и заполнение пустот между микроструктурами водой является проблематичным. Такая поверхность характеризуется как супергидрофобная.

Значения работы адгезии, вычисленные по формуле $W_{a}=\sigma_{\mathrm{lg}}\left(1+\cos \theta_{w}\right)$ (где $W_{a}-$ работа адгезии, $\sigma_{\mathrm{lg}}=73.5 \mathrm{~mJ} / \mathrm{m}^{2}$ - поверхностная энергия на границе жидкость-газ, $\theta_{w}-$ наблюдаемый краевой угол), для образцов типа 1, 2 и 3 составили 95.55, 36.75 и $8.82 \mathrm{~mJ} / \mathrm{m}^{2}$ соответственно. 


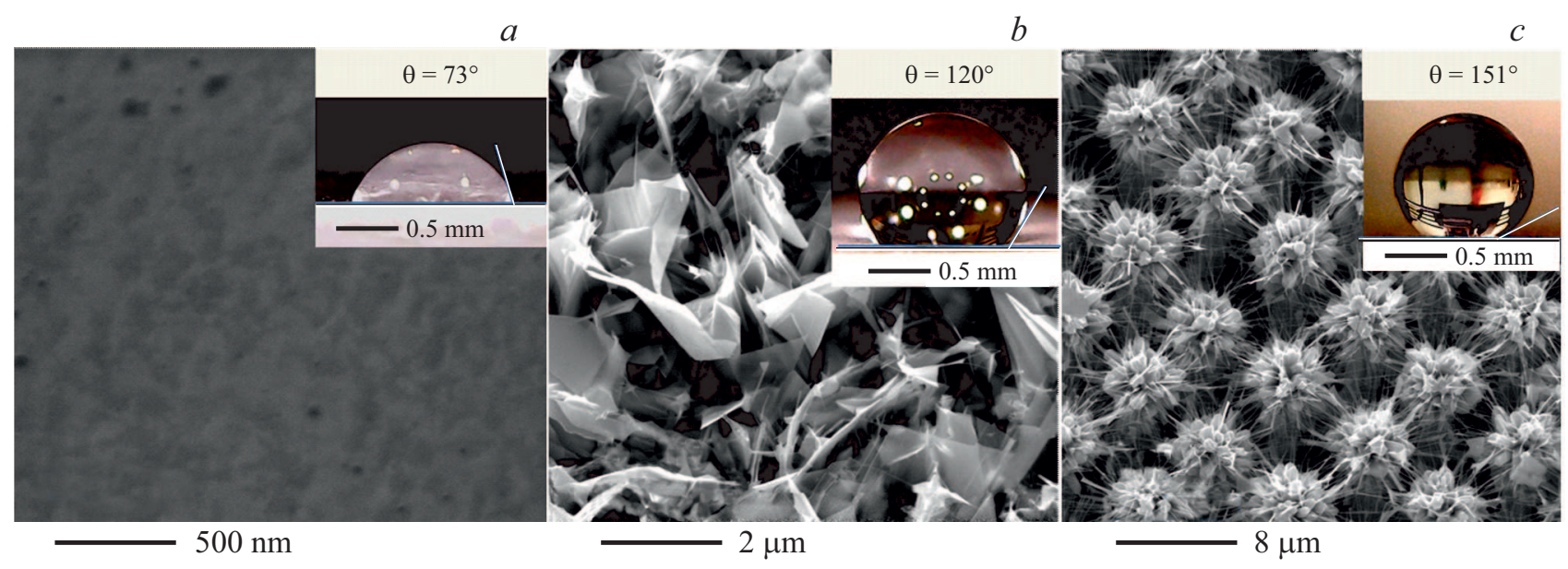

Рис. 1. Электронно-микроскопические изображения поверхности образцов $\mathrm{ZnO}$ типа 1 (a), 2 (b) и 3 (c). На вставках соответствующие формы нанесенных на эти поверхности капель воды с указанием контактных углов.

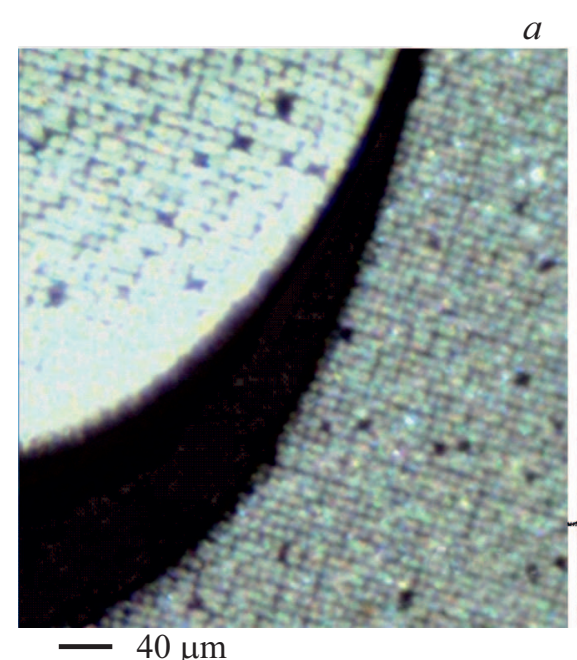

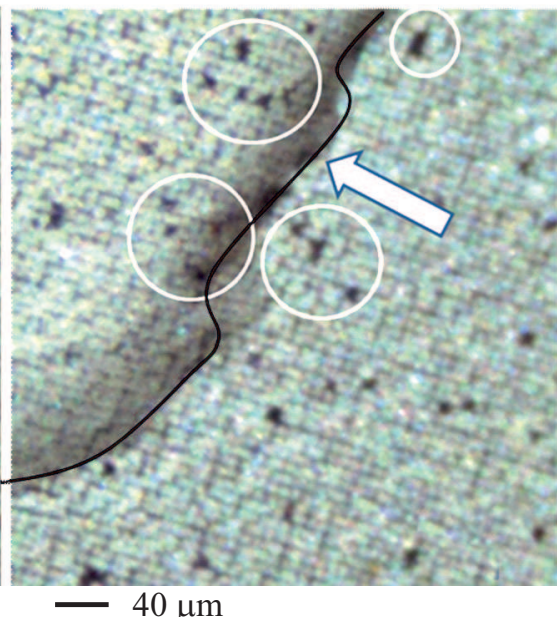

$b$

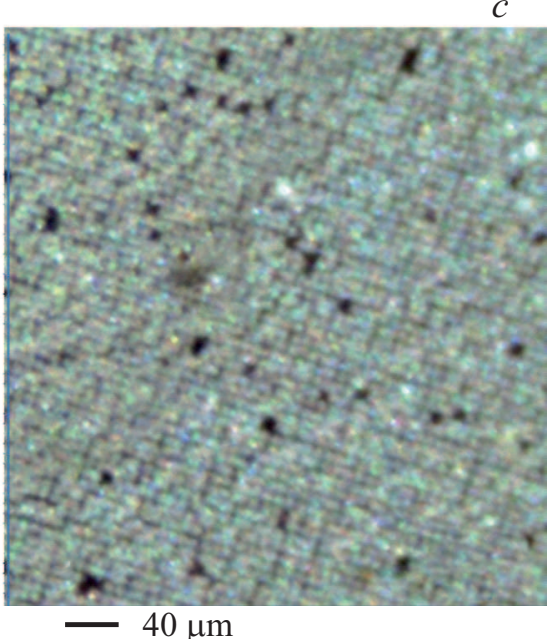

Pис. 2. Оптические изображения формы капли воды на поверхности образца типа 3 с топографическими дефектами через 1 (a), $3(b)$ и $7 \mathrm{~s}(c)$ после нанесения. Светлыми окружностями выделены микродефекты, стрелкой указана область с наибольшей скоростью перемещения стенки капли воды.

На следующем этапе исследовался образец типа 3, на который предварительно наносились топографические дефекты с линейными размерами порядка $8-22 \mu \mathrm{m}$, которые с различной плотностью были распределены вдоль поверхности (рис. 2, темные точки на оптическом изображении). Исследовались формы капель воды радиусом 0.7 и $2 \mathrm{~mm}$ на дефектной поверхности (рис. 2). Если при радиусе капель $0.7 \mathrm{~mm}$ были получены результаты, аналогичные результатам для типа 3 (рис. $1, c$ ), то при увеличении радиуса до $2 \mathrm{~mm}$ наблюдалась полная потеря гидрофобных свойств. Следовательно, увеличение размера капель воды, осажденных на микроструктурированную поверхность с топографическими дефектами, является фактором, приводящим к потере устойчивости состояния Касси. Можно отметить (рис. 2, стрелка, светлые окружности), что скорость перемещения видимой границы капли воды максимальна там, где максимальна плотность дефектов. Для объяснения наблюдаемого эффекта необходимо иметь в виду зависимость давления, оказываемого каплей воды на исследуемую поверхность, от линейных размеров капли. Рассмотрим параметр $a$, который определяет характерные размеры капель воды, при которых начинают сказываться гравитационные эффекты. Вес капли воды, определяющий величину силы давления на исследуемую поверхность, пропорционален $a^{3}$. В то же время максимальный радиус основания капли, согласно [16], пропорционален параметру $a$ при условии постоянства контактного угла $\theta$ для данной поверхности образца. В соответствии с этим сила давления, приведенная к единице площади контакта, будет увеличиваться пропорционально параметру $a$. В области дефекта сила давления со стороны капли воды уравновешивается только силой натяжения, в то время как в остальной (бездефектной) области контакта к силе 
натяжения добавляется сила реакции опоры. Это приведет к нарушению равновесия на границе капли воды, непосредственно смыкающейся с дефектом поверхности образца, и будет способствовать увеличению кривизны поверхности мениска жидкости. В дальнейшем кривизна поверхности мениска жидкости достигнет критического значения, при котором краевой угол с вертикальными стенками станет равным краевому углу на плоской поверхности. В результате жидкость начнет скользить вдоль стенок, и это сразу приведет к заполнению полостей дефекта. Следует заметить, что в случае малых размеров капель воды, для которых гравитационные эффекты несущественны, отмеченное выше увеличение кривизны в области дефекта будет незначительным. Также следует учитывать факт увеличения внутреннего давления Лапласа, направленного к центру капли воды, при уменьшении ее размера. Эти обстоятельства определяют супергидрофобность образца типа 3 для малых размеров капель воды. Наличие же микрометровых дефектов можно считать частным случаем влияния внешнего давления на стабильность состояния Касси.

Таким образом, в работе приводятся результаты исследования гидрофобных свойств микроструктур $\mathrm{ZnO}$. Рассмотрены три варианта образцов с различной шероховатостью и морфологией поверхности: с наноразмерной шероховатостью, с пластинчатой микроструктурой поверхности, с многомодальной шероховатостью на микро- и наноуровне. Показано, что состояние Венцеля реализуется в случае поверхности $\mathrm{ZnO}$ с нанометровой шероховатостью, тогда как для микроструктурированных образцов наблюдается состояние Касси. Для образца с многомодальной шероховатостью поверхности достигнуто супергидрофобное состояние с краевым углом, равным $151^{\circ}$, и работой адгезии $8.82 \mathrm{~mJ} / \mathrm{m}^{2}$. Продемонстрировано, что наличие микрометровых дефектов на поверхности приводит к нестабильности состояния Касси и при увеличении радиуса капель воды реализуется переход Касси-Венцеля.

\section{Благодарности}

Авторы выражают благодарность Л.А. Задорожной и А.М. Ополченцеву за помощь в проведении исследований.

\section{Финансирование работы}

Исследование выполнено с использованием оборудования ЦКП ФНИЦ „Кристаллография и фотоника“ в рамках выполнения работ по государственным заданиям ФНИЦ „Кристаллография и фотоника“ РАН и ДФИЦ РАН, а также при поддержке Российского фонда фундаментальных исследований (грант № 20-08-00598).

\section{Конфликт интересов}

Авторы заявляют, что у них нет конфликта интересов.

\section{Список литературы}

[1] Mahalakshmi S., Hema N., Vijaya P.P. // BioNanoSci. 2020. V. 10. P. $112-121$. https://doi.org/10.1007/s12668-019-00698-w

[2] Shitole A.A., Raut P.W., Sharma N., Giram P., Khandwekar A.P., Garnaik B. // J. Mater. Sci.: Mater. Med. 2019. V. 30. P. 51. https://doi.org/10.1007/s10856-019-6255-5

[3] Shaban M., Mohamed F., Abdallah S. // Sci. Rep. 2018. V. 8. P. 3925.

[4] Myint M.T.Z., Kumar N.S., Hornyak G.L., Dutta J. // Appl. Surf. Sci. 2013. V. 264. P. 344-348.

[5] Sharma D., Bhowmick S., Das A., Kanjilal A., Saini C.P. // Mater. Res. Express. 2019. V. 6. P. 095047.

[6] Клочко Н.П., Клепикова Е.С., Копач В.Р., Хрипунов Г.С., Мягченко Ю.А., Мельничук Е.Е., Любов В.Н., Копач А.В. // ФТП. 2016. Т. 50. В. 3. С. $357-368$.

[7] Butashin A.V., Muslimov A.E., Kanevsky V.M., Deryabin A.N., Pavlov V.A., Asadchikov V.E. // Cryst. Rep. 2013. V. 58. P. $483-487$.

[8] Gates B.D., Xu Q., Stewart M., Ryan D., Willson C.G., Whitesides G.M. // Chem. Rev. 2005. V. 105. P. 1171-1196.

[9] Pozzato A., Zilio S.D., Fois G., Vendramin D., Mistura G., Belotti M., Chen Y., Natali M. // Microelectron. Eng. 2006. V. 83. P. 884-888.

[10] Bhushan B., Jung Y.C. // Prog. Mater. Sci. 2011. V. 56. P. 1108.

[11] Yuan Y., Lee T.R. // Surface science techniques / Eds G. Bracco, B. Holst. Springer Ser. in Surface Sciences. Berlin-Heidelberg: Springer, 2013. V. 51. P. 3-34.

[12] Гиваргизов Е.И. Рост нитевидных и пластинчатых кристаллов из пара. М.: Наука, 1977. 303 с.

[13] Муслимов А.Э., Исмаилов А.М., Бабаев В.А., Каневский В.М. // Поверхность. Рентгеновские, синхротронные и нейтронные исследования. 2019. № 12. Р. 61-65.

[14] Muslimov A.E., Ismailov A.M., Babaev V.A., Kanevscy V.M. // Cryst. Rep. 2019. V. 64. P. 806-811.

[15] Borissov D., Pareek A., Renner F.U., Rohwerder M. // Phys. Chem. Chem. Phys. 2010. V. 12. P. 2059-2062.

[16] Марков И.И., Батурин М.В., Иванов М.Н., Напольская Г.Ю. // Вестн. СевКавГТУ. 2009. № 2. С. 51-58. 